\title{
Performance Analysis of Frostless Heat Exchanger by Spreading Antifreeze Solution on Heat Exchanger Surface*
}

\author{
Young-Soo CHANG** \\ **Department of Advanced Fermentation Fusion Science and Technology, Kookmin University \\ 861-1, Chongnung-dong, Songbuk-gu, Seoul 136-702, Korea \\ E-mail:yschang@kookmin.ac.kr
}

\begin{abstract}
The effect of antifreeze solution liquid film on the frost prevention is experimentally investigated. It is desirable that the antifreeze solution spreads widely on the heat exchanger surface forming thin liquid film to prevent frost nucleation while having small thermal resistance across the film. A porous layer coating technique is adopted to improve the wettability of the antifreeze solution on heat exchanger surface. The antifreeze solution spreads widely on the heat exchanger surface with $100 \mu \mathrm{m}$ thickness by the capillary force resulted from the porous structure. It is observed that the antifreeze solution liquid film prevents a heat exchanger from frosting. The reductions of heat and mass transfer rate caused by the thin liquid film are only $1-2 \%$ compared with those for non-liquid film surface.
\end{abstract}

Key words: Frost-Free, Antifreeze Solution, Porous Layer

\section{Nomenclature}

A heat transfer area, $\mathrm{m}^{2}$

$g \quad$ acceleration of gravity, $\mathrm{m} / \mathrm{s}^{2}$

$h \quad$ heat transfer coefficient, $\mathrm{W} / \mathrm{m}^{2} \mathrm{~K}$

$h_{D} \quad$ mass transfer coefficient, $\mathrm{kg} / \mathrm{m}^{2} \mathrm{~s}$

$i_{f g} \quad$ latent heat of vaporization, $\mathrm{J} / \mathrm{kg}$

$Q \quad$ heat transfer rate, $\mathrm{W}$

$\mathrm{Re}_{f} \quad$ film Reynolds number

$T$ temperature, ${ }^{\circ} \mathrm{C}$

$V \quad$ air volume flow rate, $\mathrm{m}^{3} / \mathrm{h}$

$w \quad$ humidity ratio, $\mathrm{kg} / \mathrm{kg}$

\section{Greek letters}

$\Gamma \quad$ mass flow rate per unit surface width of antifreeze solution, $\mathrm{kg} / \mathrm{ms}$

$\delta \quad$ liquid film thickness, $\mathrm{m}$

$\mu_{l} \quad$ viscosity of antifreeze solution, $\mathrm{kg} / \mathrm{ms}$

$\rho_{l} \quad$ density of antifreeze solution, $\mathrm{kg} / \mathrm{m}^{3}$

${ }^{*}$ Received 29 Nov., 2010 (No. 10-0569) [DOI: 10.1299/jtst.6.123]

Copyright $(\mathcal{2} 2011$ by JSME

\section{Subscripts}

a air

$L \quad$ latent

$l \quad$ liquid surface

$s \quad$ sensible 


\section{Introduction}

In an air-source refrigerating system, when a surface temperature of an evaporator drops below a freezing point of water (i.e. $0^{\circ} \mathrm{C}$ ), water vapor around the evaporator loses its heat by the surface of the low temperature evaporator, and thus frost is formed on the surface of the evaporator. As frost forms on a surface of a heat exchanger, a degradation of the heat exchange efficiency thereof is brought about. When the frosting is continued for some time, the frost grows to be a thick frost layer and the frost layer functions as an insulation layer between the cold surface of the evaporator and the air, thereby degrading heat transfer efficiency. Due to the consecutive growth of the frost layer, an area of the air passage is reduced, which causes an air side pressure loss to increase. Such a pressure loss affects operational characteristics of an air blower for blowing air across the evaporator, thereby reducing an air flow rate at the evaporator. That is, heat transfer performance of the evaporator is degraded because the air flow rate is reduced, and consequently, the refrigerating system may be fatally damaged. Accordingly, a defrosting process for melting and removing the frost layer formed on the surface should be performed periodically.

Various methods for removing the frost layer have been developed. ${ }^{(1,2)}$ Hot gas defrosting method, an electric defrosting method and a cycle reversing defrosting method are commonly used. These defrosting processes bring about several problems. As a refrigerating system cannot be operated continuously during the defrosting operation, refrigeration performance decreases. Additionally, as an extra heat is supplied for the defrost process, additional energy is required to remove the extra heat when the refrigerating cycle is re-operated. ${ }^{(3)}$

A growing process of the frost layer comprises three steps: crystallizing period, frost layer growing period and frost layer maturing period. ${ }^{(4)}$ When water vapor in the air condenses, the condensing vapor passes the transition through a supersaturated liquid state and freezes, generating a frost crystal nucleus. Then, a frost layer begins to be generated centering on the frost crystal nucleus. Accordingly, if the supersaturated liquid is prevented from freezing into a frost crystal nucleus, the generation and growth of the frost on a surface of evaporator may be prevented.

This research is based on the idea of that a frost on the surface of heat exchanger can be prevented if antifreeze solution is sprayed on its surface, where an antifreeze solution liquid film suppresses frost crystal nucleus generation by absorbing supersaturated water. ${ }^{(5,6)}$ However, liquid film of antifreeze solution should be as thin as possible because antifreeze solution itself gets into another thermal and flow resistance of the heat exchanger. Therefore, a small amount of the antifreeze solution should be supplied on the surface of the evaporator to reduce heat transfer resistance as well as air flow resistance.

In this study, a porous layer coating technique is adopted to improve wettability of antifreeze solution on the heat exchanger surface. Even if a small amount of the antifreeze solution is supplied, it spreads widely on the surface of the evaporator to prevent local formation of a frost layer by unequal distribution of sprayed antifreeze solution. The objective of this study is to investigate the effect of antifreeze liquid film on a frostless heat exchanger, capable of preventing degradation of performance of a heat exchanger by suppressing frost crystal nucleus causing growth of frost and wettability enhancement of antifreeze solution on porous layer coating surface.

\section{Frost Prevention of Plate Heat Exchanger}

\subsection{Porous layer coating}

Porous layer coating technique is applied on the surface of heat exchanger to improve wettability of antifreeze solution. ${ }^{(7,8)}$ Schematic diagram of the surface where porous layer is coated is shown in Fig. 1. Antifreeze solution can cover the surface with thin liquid film 
because liquid that is supplied on the surface spreads through porous layer by capillarity. ${ }^{(9)}$ Antifreeze solution wettability on aluminum surface with porous layer coating is enhanced more remarkably than that on treated surface with hydrophilic polymer which is used often for evaporator as well as that on bare aluminum surface.

Porous layer can be formed by coating solid particles on the surface using thermal spray process or adhering solid particles to the surface using suitable reactive adhesive. In this research, heat exchanger surface is coated with a mixture of silica powder of $10-30$ $\mu \mathrm{m}$ diameter and reactive adhesive and thickness of porous layer is about $50 \mu \mathrm{m}$.

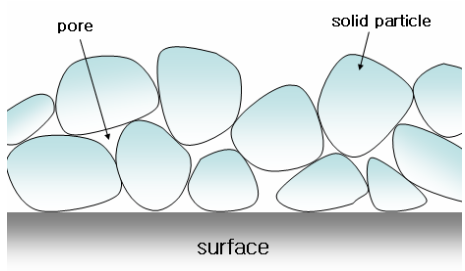

Fig. 1 Schematic of porous layer coating.

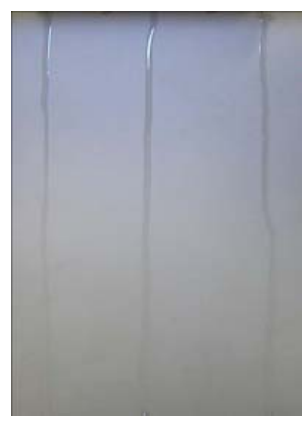

(a) bare surface

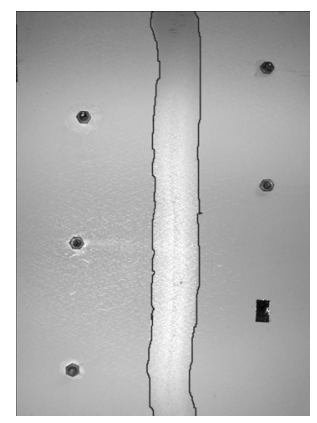

(b) porous layer coating

Fig. 2 Wetting shape on the vertical plate.

Wettability of antifreeze solution is tested on the surface of porous layer coated plate as well as bare aluminum plate. Fig. 2 shows typical results of wetting shapes on two types of vertical plate surfaces obtained by the photographic observation. A small amount of antifreeze solution is supplied at the top of plate surfaces at room temperature. It is clear that the motion of stream on a vertical surface is driven by gravity, and that the shear stress at the liquid-solid interface is much greater than at the liquid-air interface. It is also apparent that surface tension should play a major role in determining a motion. When a liquid flows down a flat surface, several different flow regimes can be observed, depending on the flow rate and the physical properties of the liquid-solid surface system. When the flow is 0.3 $\mathrm{g} / \mathrm{min}$ at vertical surface of bare aluminum plate, a single laminar rivulet which has $6 \mathrm{~mm}$ width is formed as shown in Fig. 2 (a). On the porous coating surface in Fig. 2 (b), wetting width of flow stream increases greatly by $20-40 \mathrm{~mm}$ due to capillarity.

\subsection{Experiment on plate heat exchanger}

The experimental setup is constructed as shown in Fig. 3 to observe antifreeze solution wettability and its effect on heat transfer performance, when antifreeze solution is supplied on the heat exchanger surface. Test setup consists of a plate heat exchanger, an antifreeze solution spraying device, a chiller which is for generating low temperature brine to be supplied to the plate heat exchanger as a refrigerant and also regulating the temperature of antifreeze solution, and an air conditioner to supply air of constant temperature and humidity. Air duct that encloses aluminum plate surface is composed of transparent acrylic plastic, so that observation of plate heat exchanger surface is possible. The width of air flow passage at plate heat exchanger is $10 \mathrm{~mm}$.

An antifreeze solution supplying device is installed to maintain thin liquid film on the heat exchanger surface as shown in Fig. 3. In this study, three nozzles are positioned at the top of plate surface, and a small amount of antifreeze solution falls in drops and spreads completely on the heat exchanger surface. Because the amount of supplied antifreeze solution is very small, mass flow rate is measured using a balance and a stopwatch.

A plate heat exchanger consists of three layers. The front layer is aluminum plate where heat and mass transfer with moist air occur, intermediate layer is Bakelite plate of 1 $\mathrm{mm}$ thickness to measure the heat flux, and the end layer is copper plate which have 
multiple flow paths for brine flow inside the layer to reduce and control the temperature of aluminum plate surface. Aluminum plate is used as heat exchanger surface in contact with moist air to mimic aluminum fin of fin-tube heat exchanger. The size of aluminum plate is $200 \mathrm{~mm} \times 300 \mathrm{~mm} \times 5 \mathrm{~mm}$. Contact resistances among each layer are minimized by applying thermal grease on contact surfaces of each layer. T-type thermocouples are attached on both sides of Bakelite plate and back side of aluminum at the positions in Fig. 4.

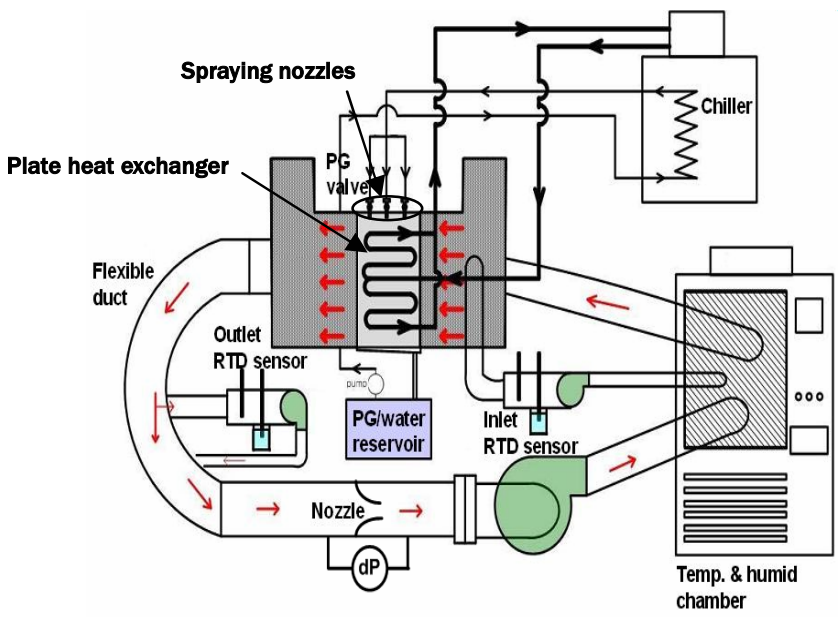

Fig. 3 Schematic of performance test setup.

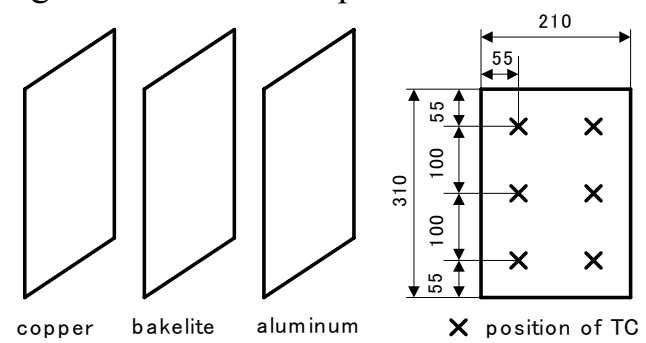

Fig. 4 Schematic of a plate heat exchanger.

Wettability of antifreeze solution at ambient temperature is measured on the surface of porous layer coated plate, and compared to that of bare aluminum plate by visualization experiment using CCD camera.

All the test conditions for frost prevention and heat transfer performance are listed in Table 1. Relative humidity of supplied air is varied from $50 \%$ to $70 \%$, and air inlet temperature and surface temperature of aluminum plate are kept by $20{ }^{\circ} \mathrm{C}$ and $-10{ }^{\circ} \mathrm{C}$, respectively. Air flow rate ranges from 31 to $51 \mathrm{~m}^{3} / \mathrm{h}$, which corresponds to $3500 \sim 6000$ of air side Reynolds number. Propylene glycol/water mixture is selected as an antifreeze solution, which is prepared beforehand enough quantity to supply to heat exchanger during test. The concentration of the antifreeze solution is maintained by $50 \%$ during the tests.

Table 1 Test conditions on plate heat exchanger

\begin{tabular}{cc}
\hline Descriptions & Values \\
\hline Plate temperature $\left[{ }^{\circ} \mathrm{C}\right]$ & -10 \\
Air inlet temperature $\left[{ }^{\circ} \mathrm{C}\right]$ & 20 \\
Relative humidity $[\%]$ & $50,60,70$ \\
Air flow rate $\left[\mathrm{m}^{3} / \mathrm{h}\right]$ & $31,42,51$ \\
Supplied brine flow rate $[\mathrm{g} / \mathrm{min}]$ & $3,6,9$ \\
\hline
\end{tabular}

Test data of temperature, pressure and mass flow rate are collected by personal computer. RTD(Resistance Temperature Detector) sensors, a nozzle type air flow meter and 
a pressure transducer are used to measure air side temperature, humidity, flow rate and pressure loss as shown in Fig. 3. RTD(Resistance Temperature Detector) sensors and Coriolis force mass flow meters are installed to measure the temperature and mass flow rate of antifreeze solution and brine.

\subsection{Results on plate heat exchanger}

In Fig. 5 (a), typical photography of frost layer that forms on the surface of aluminum plate where antifreeze solution is not supplied is shown, and with the lapse of frosting time, the frost thickness increases rapidly. By adopting porous layer coating technique in this study, Fig. 5 (b) shows frost formation can be successfully prevented by antifreeze solution liquid film. That is, the antifreeze solution liquid film spreads widely on the aluminum plate surface with porous coating, which prevents the formation of frost layer on the heat exchanger surface. The antifreeze solution is supplied at the same temperature with heat exchanger surface to exclude the effect by temperature difference.

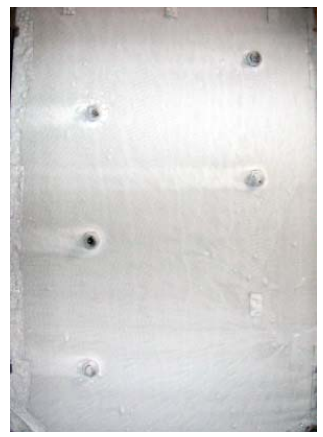

(a) Frosting surface

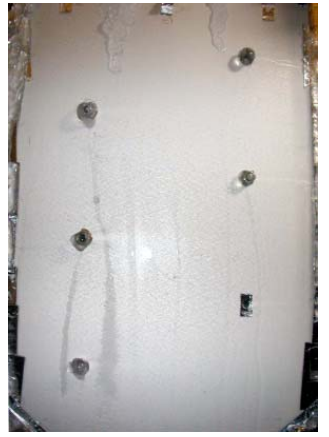

(b) frost-less surface

Fig. 5 Photography of aluminum plate under frost condition.

When the heat exchanger surface is in contact with moist air at the temperature below the dew-point for the air or freezing point, condensation or frosting of water vapor will occur on the heat exchanger surface. Both temperature and humidity of air decrease during condensation or frosting process, therefore sensible and latent heat transfer occur simultaneously. Heat transfer rate from moist air to liquid film at a temperature below the air dew-point is expressed as following using double potential model.

$$
\begin{aligned}
& Q_{S}=h A\left(T_{a}-T_{l}\right) \\
& Q_{L}=h_{D} A\left(w_{a}-w_{l}\right) i_{f g}
\end{aligned}
$$

where $h$ is sensible heat transfer coefficient, and $h_{D}$ is mass transfer coefficient. Equation (1) describes sensible heat transfer rate driven by temperature difference of air and liquid film. Equation (2) gives latent heat transfer rate by an amount of water condensate from moist air to antifreeze solution film.

Temperature and humidity at the interface between liquid film and air are evaluated by assuming that moist air is saturated at the interface. When antifreeze solution covers the heat exchanger surface below freezing point, heat transfer performance is analyzed using equations (1) and (2), and mass transfer coefficients are calculated from experimental data.

When antifreeze solution spreads on heat exchanger surface, heat and mass transfer coefficients of air side are displayed in Fig. 6 with respect to air flow rate. As you see trend line that is marked in solid line, heat and mass transfer coefficients increase with increasing air flow rate.

Uncertainty in experimental results are estimated using the method proposed by Kline and McClintock, ${ }^{(10)}$ and the results are summarized in Table 2. 


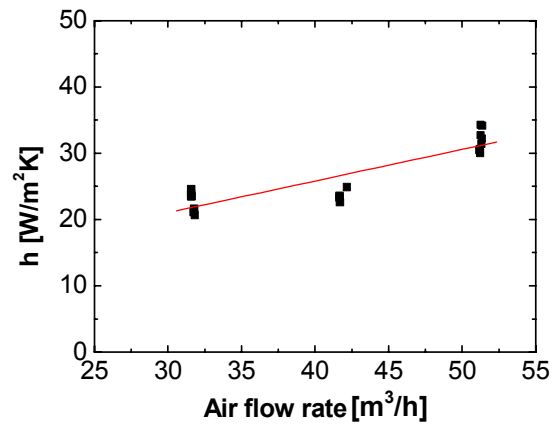

(a) Heat transfer coefficient

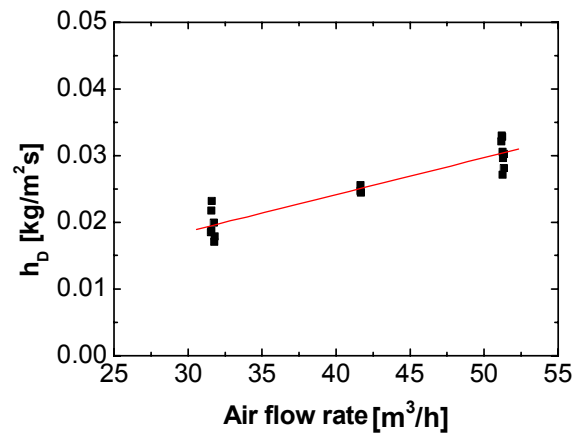

(b) Mass transfer coefficient

Fig. 6 Heat and mass transfer coefficient of air side with respect to air flow rate.

Table 2 Uncertainty of experimental results

\begin{tabular}{ccccc}
\hline$V$ & $Q_{s}$ & $h$ & $Q_{L}$ & $h_{D}$ \\
\hline $41 \mathrm{~m}^{3} / \mathrm{h}$ & $11.17 \%$ & $11.34 \%$ & $21.39 \%$ & $21.48 \%$ \\
$51 \mathrm{~m}^{3} / \mathrm{h}$ & $11.02 \%$ & $11.21 \%$ & $19.87 \%$ & $19.96 \%$ \\
\hline
\end{tabular}

Antifreeze solution flows down plate heat exchanger by gravity and absorbs condensed water from air to prevent frost formation. If ignoring shear force by air flow and buoyancy effect, the liquid film thickness is expressed as functions of viscosity, density and mass flow rate per unit surface width of antifreeze solution.

$$
\delta=\sqrt[3]{\frac{3 \mu_{l} \Gamma}{g \rho_{l}^{2}}}
$$

It is considered that supplied antifreeze solution spreads on heat exchanger surface with the same thickness. Using equation (3), liquid film thickness is calculated in Fig. 7 as a function of film Reynolds number. The liquid film is very thin and its thickness ranges from 100 to $180 \mu \mathrm{m}$, and film Reynolds number is defined as follows.

$$
\operatorname{Re}_{f}=\frac{4 \Gamma}{\mu_{l}}
$$

The liquid film by antifreeze solution may become another thermal resistance of the heat exchanger. From the Nusselt analysis, ${ }^{(1)}$ assuming that heat transfer across liquid film is due to conduction only. The heat transfer performance reductions by liquid film are presented in Fig. 8 as a function of film Reynolds number. Although heat and mass transfer performance decrease, as film Reynolds number increases, performance deterioration is very small by $1-2 \%$.

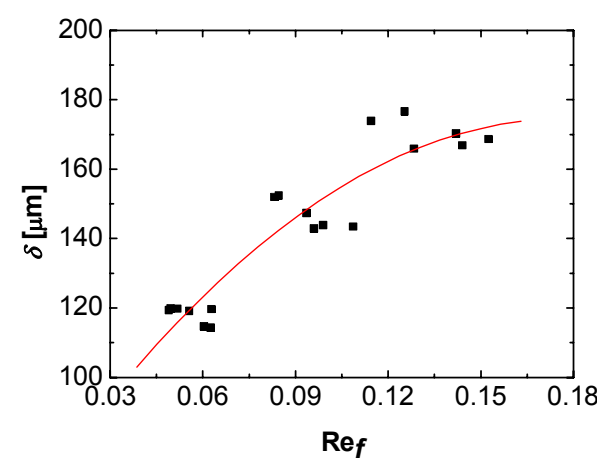

Fig. 7 Liquid film thickness with film Reynolds number.

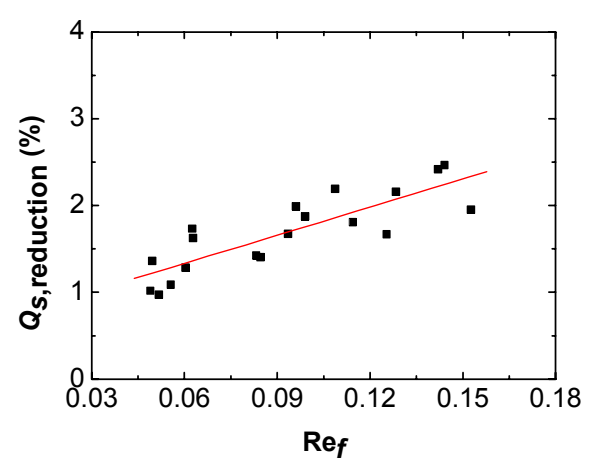

Fig. 8 Degradation in heat transfer performance by liquid film. 


\section{Frost Prevention of Fin-Tube Heat Exchanger}

\subsection{Experiment on fin-tube heat exchanger}

The performance of fin-tube heat exchanger adopting frost prevention technique explained in the above section is experimentally investigated and compared to that of frosted heat exchanger. Two types(A and B) of counter cross-flow type heat exchangers are used in the test rig, which have the same specifications except fin spacing; $5 \mathrm{~mm}$ for A type and $3 \mathrm{~mm}$ for B type.

The surface of the evaporator is coated with a mixture of fine solid particles by spraying or dipping method, ${ }^{(8)}$ the coating layer has a porous structure providing the improved wettability, even if a small amount of the antifreeze solution is applied on the surface of the evaporator, antifreeze solution can be widely spread on the surface of the evaporator and prevents local formation of a frost layer by unequal distribution of sprayed antifreeze solution. As the surface of the heat exchanger is coated in a form of thin liquid film, drops of the antifreeze solution do not scatter and leak outside of the heat exchanger and heat transfer resistance between the heat exchanger and air as well as flow resistance of flowing air can be minimized.

All the tests are performed inside thermal chamber, where air temperature and humidity are controlled and test conditions are listed in Table 3. Propylene glycol/water mixture is selected as antifreeze solution, and the concentration of antifreeze solution is maintained by $50 \%$ during the tests.

Table 3 Test conditions and heat exchanger specifications in this study

\begin{tabular}{cc}
\hline Descriptions & Values \\
\hline Initial air flow rate, $\mathrm{m}^{3} / \mathrm{min}$ & $3.15,4.73,6.3$ \\
Air inlet temperature, ${ }^{\circ} \mathrm{C}$ & 7 \\
Air inlet relative humidity, $\%$ & 88 \\
Brine temperature, ${ }^{\circ} \mathrm{C}$ & $150,200,250$ \\
Tube outer diameter, $\mathrm{mm}$ & $-13,-15$ \\
Tube arrangement, column x row & 9.52 \\
Heat exchanger size, $\mathrm{H} \times \mathrm{D} \times \mathrm{L} \mathrm{mm}$ & $5 \times 6$ \\
\hline
\end{tabular}

\subsection{Results on fin-tube heat exchanger}

In Fig. 9, typical photography of frost layer that forms on the surface of heat exchanger are shown with the lapse of time. As frosting is continued, the frost thickness increases rapidly. Due to the continuous growth of the frost layer, the area of the air passage is reduced. As shown in Fig. 10(a), air side pressure loss increases with time. Therefore, heat transfer performance of the evaporator is much degraded (see Fig. 10(b)). After 80 minutes, most frost layers of adjacent fins come in contact, so that air passage is almost blocked. Type B heat exchanger with $3 \mathrm{~mm}$ fin spacing shows higher performance by wider heat transfer area than type A heat exchanger with $5 \mathrm{~mm}$ fin spacing at the initial stage, however, in 45 minutes the performance of type B heat exchanger becomes lower than that of type A heat exchanger. The major factor causing the performance degradation is assessed as the reduction of air flow rate by passage blocking.

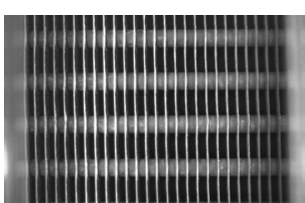

(a) $0 \mathrm{~min}$

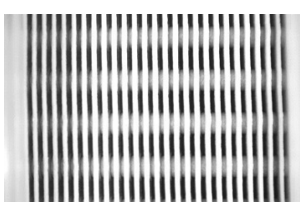

(b) $20 \mathrm{~min}$

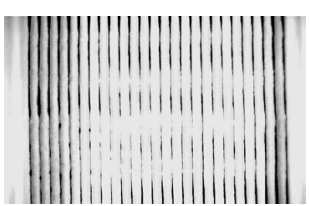

(c) $60 \mathrm{~min}$

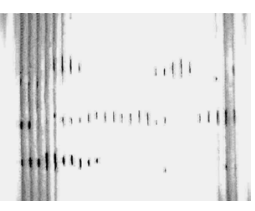

(d) $80 \mathrm{~min}$

Fig. 9 Photography of type A heat exchanger under frost condition. 


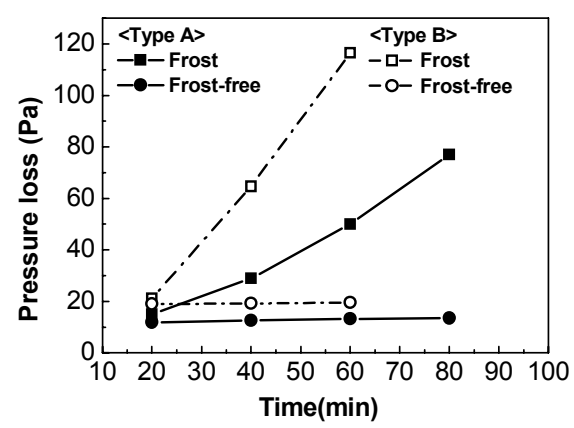

(a) Air pressure loss

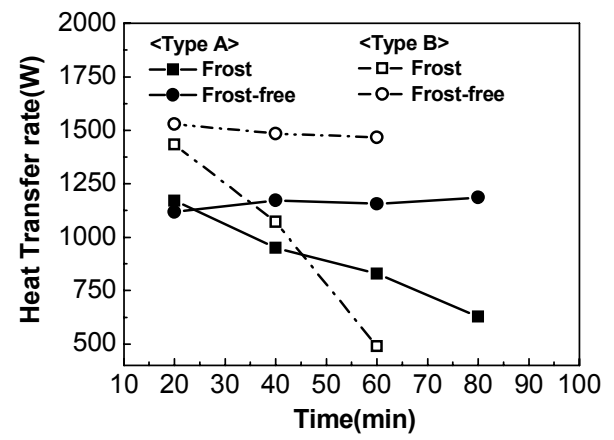

(b) Heat transfer rate

Fig. 10 Performance variation with time under frost and frost prevention condition $\left(V=3.15 \mathrm{CMM}\right.$ and $\left.m_{b}=200 \mathrm{~g} / \mathrm{min}\right)$.

By adopting frost prevention technique in this study, Fig. 11 shows frost formation can be successfully prevented by antifreeze solution liquid film. That is, the antifreeze solution liquid film spreads widely on the heat exchanger surface by solution spraying device and porous coating on heat exchanger surface, which prevents the formation of frost layer. Contrary to heat transfer reduction of frosted evaporator, the performance of frost-less heat exchanger remains nearly constant. As shown in Fig. 12, air side pressure loss does not increase within the test range of air flow rate and mass flow rate of sprayed antifreeze solution.

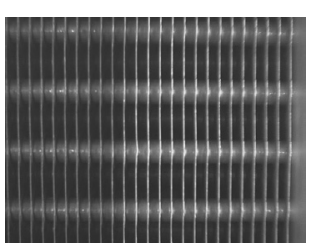

(a) $0 \mathrm{~min}$

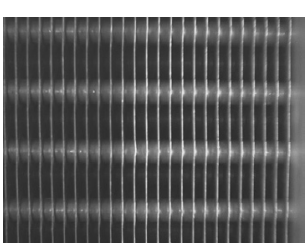

(b) $40 \mathrm{~min}$

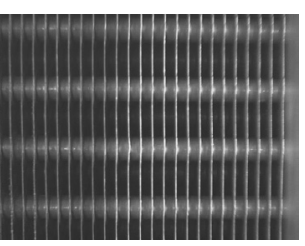

(c) $120 \mathrm{~min}$

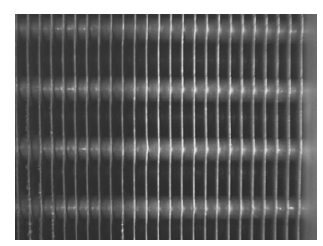

(d) $180 \mathrm{~min}$

Fig. 11 Photography of type A heat exchanger under frost prevention condition.

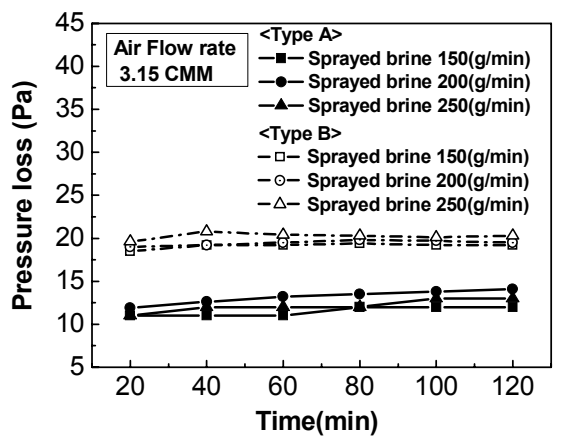

(a) Constant initial air flow rate

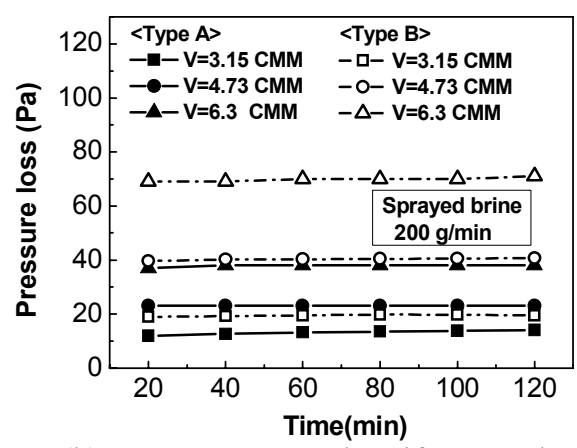

(b) Constant sprayed antifreeze solution

Fig. 12 Air pressure loss variations with time under frost prevention condition.

Some problems should be considered to apply developed system. Antifreeze solution is in direct contact with air; therefore, the solution can be contaminated due to dust or air pollutants. Thus, Air filter and decontamination system will be needed to reduce and eliminate contaminants in the solution. The durability of porous layer on heat exchanger surface is an important point in the practical application. During performance test in this study, no damage could be found on the porous layer. However, further development and monitoring in situ are required to ensure long-term performance. Low flow rate of antifreeze may generate frost on the heat exchanger, but excessive antifreeze solution deteriorates the 
system performance. Therefore, the control of antifreeze solution is another factor for practical use of developed system.

\section{Conclusions}

In this study, by investigating frost prevention performance by antifreeze solution spraying on heat exchanger surface, several conclusions are drawn as follows.

(1) When porous layer coating technique is applied on the surface of heat exchanger surface, wettability of antifreeze solution is remarkably improved by capillarity.

(2) The frost formation on the surface of heat exchanger surface is prevented by thin liquid film of antifreeze solution under frosting air condition.

(3) It is possible to keep thin liquid film on heat exchanger surface, and heat transfer degradation by the liquid film is very small by $1-2 \%$ of air-side heat transfer resistance.

(4) It is observed that the antifreeze solution liquid film prevents fin-tube heat exchanger from frosting, and heat transfer performances do not degrade within the frosting test range in this study.

\section{Acknowledgment}

This work was supported by the research program 2011 of Kookmin University in Korea, and by the Industrial Strategic technology development program (10037329, Development of Desiccant-Compression Hybrid Heat Pump System using Solar Energy) funded by the Ministry of Knowledge Economy(MKE, Korea).

\section{References}

[1] Hoffenbecker, N., Klein, S. A., and Reindl, D. T., 2005, Hot Gas Defrost Model Development and Validation, International Journal of Refrigeration, Vol. 28, pp. 605-615.

[2] Wenju, H., Yiqiang, J., Minglu, Q., Long, L., Yang, Y., and Shiming, D., 2011, An Experimental Study on the Operating Performance of a Novel Reverse Cycle Hot Gas Defrosting Method for Air Source Heat Pumps, Applied Thermal Engineering, Vol. 31, pp. 363-369.

[3] Xia, Y., Zhong, Y., Hrnjak, P. S., and Jacobi, A. M., 2006, Frost, Defrost, and Refrost and its Impact on the Air-side Thermal-hydraulic Performance of Louvered-fin, flat-tube Heat Exchangers, International Journal of Refrigeration, Vol. 29, pp. 1066-1079.

[4] Hayashi, Y., Aoki, A., Adachi, S. and Hori, K., 1977, Study of Frost Properties Correlating with Frost Formation Types, Journal of Heat Transfer, Vol. 99, pp. 239 245.

[5] Chang. Y.-S. and Yun W.-N., 2005, An Experimental Study on the Frost Prevention using Micro Liquid Film of an Antifreezing Solution, Korean Journal of Air-Conditioning and Refrigeration Engineering, Vol. 17, No. 5, pp. 459 467.

[6] Oh, S.-Y. and Chang, Y.-S., 2006, Frost Prevention of Fin-Tube Heat Exchanger by Spreading Antifreezing Solution, Korean Journal of Air-Conditioning and Refrigeration Engineering, Vol. 18, No. 6, pp. 477 485.

[7] Kim, H. J. and Lee, J. H., 1992, Analysis of Evaporative Heat Transfer in a Porous Layer by Capillary Model, Transactions of KSME(B), Vol. 16, pp. 391-399.

[8] Lee, D.Y, Lee, J.W., and Kang, B. H., 2005, An Experimental Study on the Effects of Porous Layer Treatment on Evaporative Cooling of an Inclined Surface, Korean Journal of Air-Conditioning and Refrigeration Engineering, Vol. 17, No. 1, pp. 153 158.

[9] Erik, K., 1996, Wetting and Wicking, Textile Res. J., Vol 66, pp. 660-668.

[10] Holman, J. P., Experimental Methods for Engineers, $6^{\text {th }}$ Edition, Mc Graw-Hill Int. Edition, pp. 49-50.

[11] Collier, J. G. and Thome, J. R., 1994, Convective Boiling and Condensation, Clarendon Press, p.445. 